\title{
The Relationship between Creativity and Job Self-Efficacy of Physical Education Coaches in the City of Malayer
}

\author{
*Mohammad Mohammadi \\ Qumarth Azizmalayeri
}

\begin{abstract}
Department of Physical Education, Faculty of Humanities, Malayer University, Malayer, Iran
\end{abstract} *Author for Correspondence: M.Mohammadi@Malayeru.ac.ir

\author{
Doi:10.5901/mjss.2016.v7n2s2p122
}

\section{Abstract}

This study investigates the relationship between creativity and self-efficacy of sport education coaches in city of Malayer. Two questionnaires of Jazani's job creation (2003) and Betz's self- efficacy (1996) were used to collect data. The statistical study population included all male and female athletic trainers of Malayer city during the academic year of 2015-16, whom, according to the Department of Education of Malayer were 90 people; and the sample had involves all the same number of members in study population. To analyze the data and in order to determine the normality of society Kolmogorov-Smirnov test and to test the hypotheses, Pearson correlation and regression analysis were used. The result of testing hypothesis showed that there was a significant relationship between creativity and self- efficacy. In this regard, between the subscales of self-efficiency testing that are including the right self-assessment, career awareness, the ability to choose target, the ability for future planning and problem solving skill with creativeness, there are significant relationship of $\alpha=0.05$ have been existed. But between the years of service and job creativity did not exist a significant relationship of $\alpha=0.05$. We conclude that creating fields of job creativity and job self-efficiency in guidance of sports team is very effective and having of high positions. Employment of young sport coaches having high academic degrees is necessary to guidance of sport teams in Sport Sub-Departments of Ministry of Education.

Keywords: Job Creativity, Job Self-Efficacy, Sport Coaches

\section{Introduction}

One of the basic and constructive features of human is creativity which has significant affects over development, evolution and civilization man. It is also the infrastructure of scientific and artistic inventions. Studies in the field of creativity shows that it is possible by using appropriate methods fostered creative thinking (Kalhu, 2011). Lotanzfred and Avolio (2006) has been defined creativity as a compilation of ideas and individuals' or groups' approaches in a new way. Creativity and innovation are determined as one of the strong predictors of job performance in conducted researches (Memret and Roth, 2007). They also indicate that creativity is not a gift that just certain people have it. It's not an intrinsic and hereditary feature, because by using appropriate ways, creative thinking can be fostered (Kalhu, 2011). Bandura (2009) noted that the most important techniques to foster creativity precipitation are thinking or brainstorming. Lynch Jerry (2005) in his book "Creativity in Coaching" outlined in detail the characteristics of sport coaches and mentioned creativity as one of the important feature for coaching profession; he said: lack of creativity in tough and hard situation of serious, heavy and tense competitions will stagnate and eventually cause to failure of the coaches having not creativity; and continuity in failure and lack of success would remain no choice but to bear the adverse and undesirable consequences on the physical and mental of trainers and the ineffective coaches. Researchers in their studies have shown that creative people regards their future goals and perspectives of their job in order to achieve success may through career path planning should define, measure and mange their type and value of human resources toward gaining goals by coordinate them (Salmanpour et al., 2012). Some studies have dealt with the issues of creativity and job success separately; in most of them, creativity have been mentioned and investigated specially about child labouring matters rather than adults and those who are active in society. Creativity is even can be foster in adulthood. Most of studies done about job self-efficacy have been assess this variable with other ones; i.e. job creativity has been less considered as a variable along with job self-efficacy. Thus, our research question will be "Is there a relationship between creativity and self-efficacy in sport coaches?" The most common perception of creativity is that an individual offers a new and different idea (Kansl et al., 2004). Self-efficacy has been derived from the social cognitive theory by Albert Bandura (1997), the renowned 
psychologist, which refers to beliefs or judgments of the individual about him.herself abilities to perform the duties and responsibilities. Self-efficacy means how a person in order to achieve the expected goals organized and managed required methods and executed them properly (Sone, 2009). Those who have high sense of efficiency believe that they can encounter effectively with events and situations. They refer to problems as challenges not threats, so actively seek to for new opportunities. High sense of efficiency would decrease fear of failure, increase level of ambitions and will improve the ability of problem solving and analyzing thought (Saie et al., 2014; Santos, 2006). People are different in terms of selfefficacy on various issues. So a person may have high self-efficacy in carrying out a task and having low self-efficacy in performing another one. This could explain why some people do some tasks very good but could not afford to do other things (Reid, 2010). Bandura (2009) suggests that people who believe in their self-efficacy, constitutes a major part of their consciousness. Four major sources are identified to create and modify system of self-efficacy beliefs. These sources are: successful experiences, Alternative experiences, verbal and social encouraging, emotional and physiological states. Timosen (2012) concluded in a study that job self-efficacy has an important role in increasing the efficiency of employed coaches in leagues. Shinez et al. (2011) have found that there is a significant and positive relationship between job selfefficacy and reputation of managers. Also, there is a significant relationship between job self-efficacy and egoism caused by manager's renown; but there is not a significant relationship between job attitude and self-efficacy. Keshawarz et al. (2014) have declared in their study that there is not a significant relationship between job self-efficacy in Tehran's Board of Sports Directors and background and managerial level; but there is a significant relationship between self-efficacy and field of study in its self-efficacy. Kaweie et al. (2014) in a study stated that it is found no significant relationship between age, education and years of service with none of job satisfaction aspects. The difference between women and men in variables of self-efficacy of teaching and motivational needs except (safety requirements) was significant. Keshawarz et al (2014) also stated that they were only examined and explained job self-efficacy of sports managers in connection with demographic variables. Shabani Bahar et al (2013) concluded that in order to promote the success of the employee's job, they had to increase their motivation to exercise. Li yang (2009) stated in a research how personality factors (computerial self-efficacy and professional skills of information technology field), background factors (such as the power of communication and self-orientation) and creative self-efficacy are related. Dalal Nassiri et al (2012) stated that there is a significant positive relationship between creativity and innovation with job satisfaction; however, the correlation coefficient of innovation with job satisfaction is much more than job satisfaction and creativity. Innovation and creativity is the predictor of job satisfaction. Sheix Ali zadeh Harris et al (2011) in a study by the title of "creativity in organizational culture by managers of sports organizations" stated that there is no significant relationship between managers' demographic characteristics such as gender, age, education, field of study, managerial records and years of service with the level of managers' creativity. Saleh Blurdi and Pashaie Sharifi (2010) in a study concluded that there is a significant positive relationship between job satisfaction and self-awareness in private location; and job satisfaction can be predicted from one's self-consciousness in a private location. Jbuyga and Popola (2013) in a research by the title of "demographic variables and self-efficacy as affective factors in commitments of Liberians people who work in Nigeria universities" concluded that there is a significant relationship between demographic variables and self-efficacy of sample studies. Neew's research results (2010) in Taiwan hotels showed that the employees require high levels of self-efficacy to learn, responsibility and commitment to their jobs. Bringerz et al (2007) results also showed that job self-efficacy has a significant relationship with achievement in education. Joanna (2006) examined the relationship between organizational environment with creativity and innovation in America's teachers in three states and the results of his study showed that organizational environment has a positive effect on creativity and innovation. The aim of this study was to determine the relationship between creativity and job self-efficacy in sport coaches of bureau of education in Malayer city.

\section{Methods}

The methodology of the research is descriptive and correlational. The study population were consisted of all men and women sports instructors of bureau of education in the city of Malayer at academic year of 95-94 that their number was 90 , according to the Department of Education of Malayer city. In order to collect the data, we used from Nasrin Jazani's measurement of job creativity questionnaire which consists of 37 questions and reliability was 0.78 that achieved by Cronbach's alpha coefficient. Job self-efficacy questionnaire which included 20 questions was used to determine the reliability of Cronbach's alpha. The results revealed that the questionnaire which was made by Betz and colleagues in 1996; its reliability was 0.75 . This test is based on the theory of Krait (1987) that contributes to five components of correct self-assessment, career awareness, the ability to choose target, the ability to plan for future, problem solving skills. After permission of Malayer Department of Education, the study was conducted by referring to the sample groups and questionnaires were distributed and collected. To describe the information, we used from table and distribution 
histograms, percentage, central indicators and distribution statistics; and Kolmogorov-Smirnov test was used to determine the normality of society, Pearson's correlation coefficient to test the correlation coefficient and to predict the relationship between the predictor variables and the criterion, regression tests were used. Data Analysis was used by SPSS software version.

\section{Findings}

As a result of demographic data sport coaches of education bureau of Malayer indicates that $58.6 \%$ were males and $41.1 \%$ were women. The mean and standard deviation of respondents age were equal to $7.02 \pm 35.74,21.1 \%$ single and $78.9 \%$ were married, $15.6 \%$ conditional contractual, 22.2 treaty $\%, 62.2 \%$ formal contractual; the mean and standard deviation of years of service were equal to $67.7 \pm 64.12,10 \%$ associate degree, $64.4 \% \mathrm{BA}, 25.6 \%$ were MA and PhD.

Table 1: Descriptive statistics of job self-efficacy sub-scales

\begin{tabular}{|l|c|c|c|c|c|}
\hline Criterion & Mean & Standard Deviation & Mid & Min & Max \\
\hline Self Assessment & 20.4 & 59.0 & 25.4 & 3 & 5 \\
\hline Knowledge & 06.4 & 64.0 & 4 & 33.2 & 5 \\
\hline Target Choosing & 02.4 & 64.0 & 4 & 40.2 & 5 \\
\hline Planning & 91.3 & 77.0 & 4 & 1 & 5 \\
\hline Problem Solving & 96.3 & 66.0 & 4 & 2 & 5 \\
\hline Self-efficacy & 03.4 & 53.0 & 05.4 & 65.2 & 5 \\
\hline
\end{tabular}

As shown in Table 2, by increasing job creativity of the trainers, job self-efficacy also increase by the rate of 0.539 . Then, as the small significance level of $(0.000)$ from the given amount of $\alpha=0.05$, the null hypothesis based on the lack of relationship between these two variables is rejected.

Table 2: Correlation Coefficient between variables

\begin{tabular}{|l|l|c|c|l|}
\hline Independent Variable & Dependent Variable & $\begin{array}{c}\text { Correlation } \\
\text { Coefficient }\end{array}$ & $\begin{array}{c}\text { Significance } \\
\text { Level }\end{array}$ & Results \\
\hline Job Creativity & Job- Self-Efficacy & 539.0 & 000.0 & Rejection of the Null Hypothesis \\
\hline Job Creativity & Self-Assessment & 369.0 & 000.0 & Rejection of the Null Hypothesis \\
\hline Job Creativity & Awareness & 265.0 & 012.0 & Rejection of the Null Hypothesis \\
\hline Job Creativity & Target Choosing of the Coaches & 384.0 & 000.0 & Rejection of the Null Hypothesis \\
\hline Job Creativity & The Ability of Planning & 476.0 & 000.0 & Rejection of the Null Hypothesis \\
\hline Job Creativity & Problem Solving Skill & 423.0 & 000.0 & Rejection of the Null Hypothesis \\
\hline Years of Service & Self-Efficacy & $006 .-0$ & 961.0 & Acceptance of the Null Hypothesis \\
\hline
\end{tabular}

Information of Table 2 using correlation coefficient shows that there is a significant relationship between job creativity with self-efficacy, self-assessment, awareness, target choosing of the coaches, the ability of planning, problem solving skills and self-efficacy. But there is no significant relationship between creativity and years of service.

\section{Discussion and Conclusion}

The results showed that there is a relationship between job creativity and self-efficacy on sport coaches. The results of the research does not match with results of Eskandari et al. (2014), Keshawarz et al (2014), but is consistent with the results of Salmanpour et al (2012), Memret and Ruth (2007) and Timosin (2012). Job creativity means to provide a new thought or an idea to improve the quantity or quality of the organization's activities, such as increase productivity, enhance products or services, and reduce costs (Solomon, 2010). According to Bandura (2009) individual, environment and behavior have impact and interaction together, and none of these three components cannot be considered as a determinant of human behavior; on the other hand, based on cognitive - social theory people have the power of influence and changing their actions and their self-efficacy beliefs are of the most influential and the most impressive features of human characteristics. Hence it can be concluded that teachers' attitudes play a decisive role in promoting the creativity of students, regards self-efficacy, career success is strongly linked with each other. However, in order to achieve stronger results there is need for more extensive researches. There is relationship between job creativity and job self-evaluation of 
sport instructors. The results are consistent with the results of Dallal Nassiri et al (2012), Kaveie et al (2014) and Joanna (2006) and do not match with the results of Sone et al (2009) and Jachin and Ardel (2012). Since education is a timeconsuming, fruitful and difficult process at the same time in which teachers, as the beginning of an educational transformation, have the highest, best role and are responsible for it (Marwi, 2010). There are obstacles to the emergence of their creativity; and more importantly, they haven't learned how to use their creative thinking or simply they have not been taught to be creative (Soleymani, 2010). It is rooted in the self-assessment which is begun with working practices and also the effort to increase work better. In particular, high levels of self-efficacy will cause to do more and more work, effort and greater flexibility that all these behaviors lead to increase in performance. However, the results showed that there is a relationship between job creativity and job awareness of sport coaches. The results of the research are consistent with the results of Musa Khani et al. (2013), Saleh Blurdi and Pasha Sharifi (2010), Rothman and colleagues (2008) and Kalhu (2011). Awareness is thought as a personality and skill that is said has played an important role in the organizing employee's performance and managerial high efficeincy (Kalhu, 2011). Bandura (2009) states that people believes' to their self-efficacy, constitutes a major part of their consciousness. To create and change their selfefficacy belief systems constitutes a major part of their consciousness. Therefore, creativity makes a way of thinking that creates new ideas; and guide people's trend and interest towards specific objectives (Musa Khani et al., 2013). So, job creativity and knowledge can improve the quantity and quality of educational performance, the effectiveness and efficiency of motivation and competition among sport coaches of education bureau. Another result was that we found there is a relationship between job creativity and target choosing of sport coaches. The results are match with the results of Dehqan and colleagues (2008), Musa Khani et al (2013), Bringez et al (2007) and inconsistent with the results of Nilya (2008). Increasing creativity in organizations can lead to improve the quantity and quality of services, preventing waste of resources, increasing efficiency and outputs (Dehqan et al., 2008). Fung (2003) referred to target selecting in order to the maximum level of self-efficacy. Therefore job self-efficacy has to be described in twofold: 1) psychological aspect, 2) General aspect. The psychological aspect refers to the feelings of people in terms of efficiency power to do the work, and general view is about those who can use all their abilities and available features to achieve their purposes (Bringez et al., 2007). So when sport coaches have job creativeness, they will be successful in planning and determining goals in achieving their career goals. The study results also showed that there is a relationship between job creativity and job scheduling capabilities among sport coaches. The results of the research is consistent with the results of Ghasemzadeh (2010), Gharabaghi et al (2011), Dallal Nassiri et al (2012), Lee Young (2008) and Tom Reed (2010); however, the research results do not match with Saleh Bluri and Sharifi nia (2010) and Hejazi (2012). Creative features of human has always been one of the issues that attracted the mind of intellectuals; because they were aware of the fact that human owe to its creativity for culture and civilization (Gharabaghi, et al., 2011). Coaches have important roles in the success or failure of sports teams; so the most appropriate people have to be choosing to lead the teams (Timosin, 2012). Planning is a rational and wisdom process in personal, career and organizational life of every humans or community and will accelerate the realization of goals that are include streaming and continuousness, thought and wisdom, having vision frameworks and targets, guiding and directing (Shinz et al., 2011). So sport coaches should be identified the factors and variables affecting internal in all aspects of planning to have the ability to change and adapt to different situations (Tom Reed, 2010). Because athletic trainers according to their creativity should be affective in line with organizing, interpretation and helpful strategic planning and a coach can make a wisdom move in a time that with an innovative thinking be able to achieve a good planning in order to improve his.her productivity and efficiency. Another result of the study was that there is relationship between job creativity and problem solving skills among sport coaches. The study is consistent with the results of Gholami (2009), Gharabaghi et al (2011), Moradi and Rashidpur (2013), Waar and Kistans (2007), Volfolk et al (2008). Gaieneh defines creativity as a kind of problem-solving ability where different backgrounds of ideas and thoughts can relate to each other (Saif al, 2011). On the other hand, the development process of solutions to solve problems through the synergy of thought according to the situation of job perspectives and new solutions (Moradi and Rashidpur, 2013), on the other hand, given that people in working positions will face day after day with issues and more serious problems so they need creative mind. New issues and problems require new solutions and naturally, who can create these solutions. Today we are witnessing the emergence of new issues and problems that can create these solutions (Volfolk et al., 2008). In fact, solving problems, finding solutions or answers to a question, so sport coaches who have high job creativity are more successful in dealing with their problems and solving them. Finally, according to other research results there is no relationship between years of service and job self-efficacy among sport coaches. The results of the research is consistent with the results of karimzadeh et al (2008) and Keshawarz et al (2014) but do not consistent with the results of Jbuyga and Popola (2013) and Timosin (2012). Keshawarz et al (2014) have done a study to determine the predictor factors of job self-efficacy among the Tehran's Board of Sports Directors and stated that there is no significant relationship between self-efficacy and management experience. Bandura (2009) defines self-efficacy as 
people's perception and judgment skills and their abilities to do what is needed to special situations. Thus self-efficacy is a multidimensional structure which is dependent on individual and the scale of all-aspect and overall measurement to measure self-efficacy is not exist in all matters (Gholami, 2009), Therefore, creativity and self-efficacy have not any links to the sport coaches' years of service, because people with high job creativity and self-efficacy are more successful than those who have higher years of service and experiences. In order to apply the findings to the relevant authorities of Education bureau it is recommended that making fields of growing job creativity and self-efficacy in-service training to familiar the employees with the ways of job creativity and self-efficacy about sport coaches would be a proper activity; and conduct training classes to carry out the necessary measures. In general, as the results of this study and the previous studies have been considered it and since science, technology, art and skills based on the nature and subject often requires those who have creativity and self-efficacy in their job, physical education and sport are no exception, so creative and self-efficacy of the coaches has been very important factors in their success and making field of creativity fostering and job self-efficacy in guidance of sports team is very effective and of high position and using young sport coaches who have higher academic degrees to guide sport teams is necessary in Malayer city.

\section{Acknowledgements}

At the end we kindly appreciate respected authorities of Malayer University and Deputy of Research and Technology for their helps in doing this study.

\section{References}

Fung, L. (2003). "Assessment: Coaching Efficacy as Indicators of Coach Education Program Needs, Athletic Insight". The Online of Sort Psychology, 5(1): PP:12-18.

Bandura, A. (2009). Adolescent development from an agentic perspective. Perspectives on Psychological Science, 3, 110-121.

Berings, M. G. M. C., Poell, R. F., Simons, P. R. J. \& Van Veldhoven. M. J. P. M. (2007). The development and validation of the On-thejob Learning Styles.

Coelho- Filipe. (2011). Contextual Factors and the Creativity of Frontline Employees: The Mediating Effects of Role Stress and Intrinsic Motivation.

Dalal Nasiri, S., Ahmadi, A., Barzegar, M., (2012). the relationship of creativity and innovation with job satisfaction in hand made industrial workers, Innovation and creativity in social sciences, No. 3; $204-107$.

Dehghan, A.; Ghafuri, F; Ashraf Ganjavie, F. (2010). The relationship between organizational culture of sport managers with creativity of physical education teachers. Journal of Motor and Sport Science, 15, 81-71.

Effects on Job Satisfaction", Journal of Vocational Behavior, 84, 149-171.

Eskandari, M., Fathi Ashtiani, Ali; Salimi, Sayed Hussein; and Ennisi, J. (2010). Career success and the characteristics of the employees in a particular field of military, journal of military psychology, 2. 24-13.

Gboyega A., Popoola S. O. (2013). Demographic Variables and Self-efficacy as Factors Influencing Career Commitment of Librarians in Federal University Libraries in. Library Philosophy and Practice, This paper is posted at DigitalCommons@University of Nebraska - Lincoln.

Gharabakhi, H., Amir Teymouri, M.H., Maghami, H.R. (2011). the relationship between creativity with self-efficacy in theses of B.A. university students in the field of educational technology of the psychological college of Allameh Tabatabaie University; creativity and innovation in social science, first year, number 2, spring and summer.

Ghasemzadeh, M. (2010). the relationship of job self-efficacy with research performance of physical education teachers in universities of Tehran; Sport Management studies, fall of 2011; 11.

Gholami, M.T., (2009). The relationship of individual and general self-efficacy with job satisfaction of teachers in Qom province; Tehran, University of Tehran, M.A. Thesis.

Hejazi, Elahe; Sadeghi, Nahid; Khaki, Sakina Khatun (2012). The relationship between job attitudes, feeling of self-efficacy, performance with commitment, Journal of Educational Innovations. 24-2.

Hosseini, A., (2008). the nature of creativity and methods of fostering in Mash'had, Razawi Holy Area.

Joanna, K., (2006). Organizational climat \& Creativity ans InnovationCreativity and Innovation Management, Vol. 13, No. 3, pp. 187-196.

Karimzadeh Shirazi, M., Razawieh, A., Kaweh, M.H. (2008); the relationship of life quality and self-efficacy of teachers in Shehre Kurd; Journal of Medical Science university of Shahre Kurd; 2008; 10 (1): 28-35.

Kaweie, T., Ashuri, A., Habibi, M. (2014). predicting of job satisfaction based on self-efficacy beliefs, teaching self-efficacy, job stress and needs level of exceptional teachers in Lorestan Province; quarterly periodical of exceptional education, 4; 5-15.

Keshawarz, L., Sarkhosh, S. (2013). the relationship of job self-efficacy in managers and organizational commitment with job satisfaction of clients in sport and youth organization of Kerman province; Applied researches in sport management, 4, 11-19.

Keshawarz, L., Sarkhosh, S. (2013). the relationship of managers self-efficacy and the employees' organizational commitment with customers satisfaction in Administrative of sport and youth of Lorestan province; Quarterly periodical of applied researches in sport management; 4; 11-19. 
Keshawarz, L.; Brarzadeh, H; Molajafari, A. (2014). Determining the predictors of job self-efficacy in Tehran's Board of Sports Directors. Sports Management Studies February and March 2014 (27).

Kuncel, N.R. Hezlett, S. A. Ones, D. S. (2004). Academic performance, career potential, creativity, and job performance: Can one construct predict them all? Journal of Personality and Social Psychology. 1, 148-161.

Lee, Yang. (2009) .Crative Self-efficacy. received from : http...portal.acm.org. citation.

Linj. Jerry (2004). Creativity in Coachin; Translation by Kurdish M.R. et al. Bamdad Pub; First Edition

Luthans, F., Zhu, W., \& Avolio, B. J. (2006). The impact of efficacy on work attitudes across cultures. Journal of World Business, 41(2), 121-132.

Marwi, M., (2010). the relationship of job satisfaction and demographic variables among exceptional teachers of Mazandaran province; journal of exceptional education, 105, 11-20.

Memmert, D. Roth, k. (2007). The effects of non-specific and specific concepts on tactical creativity in team ball sports. Journal of Sports Sciences; 25(12): $1423-1432$.

Moradi, A.R.; Rashidpour, A. (2013). the role of creativity in the process of cultural problem solving through cultural gathering, journal of creativity, 78; 159-165.

Mrugank, V.T. and Ashwin, W.J., (2005). Motivating salesperson customer orientation: insights from the Job Characteristics Model, Journal of Business Research, 58, pp. 584-592.

Musa Khani, M., Hamidi, N., Najafi, Z. (2013). priority of affecting factors over the managers performance in education bureau using multi-dimensional decision making techniques and analyzing the hierarchy and allocating linear vector; journal of educational innovation, 32; 126-135.

Nelia (2008) "The role of self-efficacy in employee commitment" M.Com, University of South Africa (South Africa).

$\mathrm{Niu}$, Han-Jen (2010) "Investigating the effects of self-efficacy on foodservice industry employees' career commitment" International Journal of Hospitality Management 29.743-750.

Rothman, Kenneth J.; Greenland, Sander \& Lash, Timothy L., (2008). Modern epidemiology, Medicine, Barnes \& Noble. Com.

Saie, E; Naami, Abdul Zahra and Nissi, Abdul Kadhum (2014). The relationship between target choosing motivational, organizational justice, job control, self-efficacy and self-regulation with the obligation of employees' working in an industrial organization.

Saief, A. (2011). Educational psychology (eighth edition). Tehran: Dawran Pub.

Saleh Bluri, Anahita; Pasha Sharifi, Hassan (2010). Examine the relationship of self awareness in job position with job satisfaction of sales managers in Industrial Management Institute of Iran, Journal of Modern Industrial - Organization Psychology, No. 2, 27-21.

Salmanpour, Ali; Elie, Hussein; Afkham, M.R.; Shokrzadeh, M (2012). The effects of demographic factors on emotional intelligence and career success (case study in Islamic Azad University of Tabriz); Journal of Beyond Management. 20. 164-145.

Santos, Maria Bianca. (2006). Locus of control, personality and occupational characteristics as determinants of job satisfaction, wellbeing and stress in Scottish social work organizations. MA diss. Taiwan.

Schyns, B. (2011). Self-Monitoring and Occupational Self-Efficacy of Employees and Their Relation to Perceived Transformational Leadership. Current Research in Social Psychology, 7, 30--42.

Shabani Bahar, Gh; Erfani, N; Hekmati, Z (2013). Relationship of Exercise Motivation and job success rate in Kermanshah Province Department of Education employees', Journal of Applied Sport Management, No. 3, 22-11.

Sheikh Alizadeh Harriss, M., Tejari, F., Pir Alaie, E. (2011). assessing the level of creativity on organizational culture among managers of sport organizations; Journal of sport management; 11, 99-117.

Soleimani, A. (2010). Creative Training. Training magazine. Tehran: Publication of education and training.

Soonhee, K. (2009). Managerial leadership, the Climate for Creativity and innovation, and a culture of innovation and PerformanceDriven in local Government. Paper Prepared for the PMRA conference.

Timucin G. R. (2012). A Study on the Self-Efficacy of Elite Coaches Working at the Turkish Coca-Cola Academy League, The Sport journal, Vol. 4. Available at the http:www.thesportjournal.org.

Tom, Reid, (2010) Tactical and strategic contract management. Contract management. Aug 2010.vol.50.iss.8, pp68-56.

Ware, H., \& Kitsantas, A. (2007). Teacher and collective efficacy beliefs as predictors of professional commitment. Journalprofessional commitment. Journal of Educational Research, 100(5), 303-310.

Woolfolk Hoy, A., Hoy, W. K., Kurz, N. M. (2008). Teachers' Academic Optimism: The Development and Test of A New Construct. Journal of Teaching and Teacher Education, 24, 821-835. 